\title{
Can lung ultrasound predict histologic pattern of lung injury in critically ill patients with COVID-19? Author's reply
}

Renata Aparecida de Almeida Monteiro, Amaro Nunes Duarte-Neto, Paulo Hilário Nascimento Saldiva and Marisa Dolhnikoff* (D)

(c) 2021 Springer-Verlag GmbH Germany, part of Springer Nature

We thank the comments and suggestions in the letter by Avdeev et al. [1] addressing our recent article published in Intensive Care Medicine [2]. Indeed, as pointed out in the original article, we have limitations in our study since we only dealt with the most severe presentation of pulmonary coronavirus disease 2019 (COVID-19), that is, the fatalities. In fact, getting pulmonary tissue from autopsy was an unavoidable limitation and the only possible approach to establish lung ultrasound (LUS)-histological correlations, as lung biopsies are not indicated in COVID-19.

It is expected that part of the fibroproliferative changes in COVID-19-related acute respiratory distress syndrome (ARDS) undergo some regression in survivors. Severe COVID-19 pneumonia is a disease characterised by a simultaneous combination of acute and fibroproliferative changes [2, 3]; in our study, the fibroproliferative pattern was defined as any degree of fibroblastic proliferation within the interstitium and alveolar spaces, including presence of loose aggregates of fibroblasts, collagen deposition, squamous metaplasia, and possible remnants of hyaline membranes [2]. In a larger series of 41 COVID-19 autopsies, we showed that a more advanced fibrotic pattern of pulmonary lesion is present in 39\% of the patients and is associated with longer periods of hospitalisation [3]. This finding is in line with the study of Han et al., who showed lung fibrotic-like changes in 35\% of severe COVID-19 patients who had a 6-month followup chest computed tomography [4]. Therefore, the use of

*Correspondence: maridol@usp.br

Departamento de Patologia, Faculdade de Medicina da Universidade de São Paulo, Av. Dr. Arnaldo, 455, São Paulo, SP 01246-903, Brazil

\section{Springer}

LUS scores to detect fibroproliferative changes in severe COVID-19 patients can be important to conduct sequential in vivo studies aimed not only to identify the onset, but also to follow the possible partial reversibility of the pulmonary remodelling process. It may be possible that LUS scores can also be used as a complementary tool in the clinical-functional follow-up of patients on antifibrotic therapies for severe COVID-19 pneumonia [5].

\section{Declarations}

Conflicts of interest

The authors declare no conflicts of interest.

\section{Publisher's Note}

Springer Nature remains neutral with regard to jurisdictional claims in published maps and institutional affiliations.

Received: 25 February 2021 Accepted: 1 March 2021

Published online: 12 March 2021

\section{References}

1. Avdeev SN, Nekludova GV, Trushenko NV, Yaroshetskiy Al, Nuralieva GS (2021) Can lung ultrasound predict histologic pattern of lung injury in critically ill patients with COVID-19? Intensive Care Med 25:1-2

2. de Almeida Monteiro RA, Duarte-Neto AN, Ferraz da Silva LF, de Oliveira EP, do Nascimento ECT, Mauad T, Saldiva PHDN, Dolhnikoff M (2021) Ultrasound assessment of pulmonary fibroproliferative changes in severe COVID-19: a quantitative correlation study with histopathological findings. Intensive Care Med 47(2):199-207. https://doi.org/10.1007/s0013 4-020-06328-4

3. Mauad T, Duarte-Neto AN, da Silva LFF, de Oliveira EP, de Brito JM, do Nascimento ECT, de Almeida Monteiro RA, Ferreira JC, de Carvalho CRR, do Nascimento Saldiva PH, Dolhnikoff M (2021) Tracking the time course of pathological patterns of lung injury in severe COVID-19. Respir Res 22(1):32. https://doi.org/10.1186/s12931-021-01628-9

4. Han X, Fan Y, Alwalid O, Li N, Jia X, Yuan M, Li Y, Cao Y, Gu J, Wu H, Shi H (2021) Six-month follow-up chest CT findings after severe COVID-19 pneumonia. Radiology. https://doi.org/10.1148/radiol.2021203153

5. George PM, Wells AU, Jenkins RG (2020) Pulmonary fibrosis and COVID-19: the potential role for antifibrotic therapy. Lancet Respir Med 8(8):807-815. https://doi.org/10.1016/S2213-2600(20)30225-3 